\title{
Grade Dropping, Strategic Behavior, And Student 'Satisficing'
}

Lester Hadsell, State University of New York, USA

Raymond MacDermott, Virginia Military Institute, USA

\begin{abstract}
An extensive database of exam scores is studied to determine the effects of a grading policy that drops the lowest exam score. We find evidence that some students engage in strategic behavior, either by understudying for one of the exams or missing one altogether, but the vast majority of students show no evidence of strategic behavior. We also find evidence that many students "satisfice", showing how a large percentage of students passed up an expected improvement in their course grade. We find that the probability a student will choose to complete an optional final exam is inversely related to their grade going into the final. Further, the likelihood of a student completing the final exam rises with the spread between prior exam scores and falls with the points needed to raise their course grade.
\end{abstract}

Keywords: Grade dropping, student behavior, introductory finance

\section{INTRODUCTION}

ven though it is common for faculty to drop the lowest exam score when computing a course grade, the effects of such policies on student performance and behavior are not well documented. In this paper, we examine five semesters of grade data covering 1,945 students to learn more about students' choices regarding completing an optional cumulative final exam. We investigate how students react to a grade-dropping policy and how such a policy affects students' course grade. In particular, we address such questions as:

- Is there a tendency for students to under prepare for an exam when the lowest exam is dropped?

- How does a student's grade going into an optional, comprehensive final exam affect the probability of a student taking the final?

- How does the spread between scores on in-term exams affect the probability of a student taking the comprehensive final exam?

- Does the number of points a student needs to "step up" to the next course (letter) grade affect the probability of their taking the final?

- How does a grade-dropping policy affect a course's final grade distribution?

A grade-dropping policy, in which one bad exam grade no longer guarantees a poor course grade, has several potential benefits for students and instructors. ${ }^{1}$ It may increase persistence (i.e. lessen the dropout rate) and class attendance (when the last exam is not an in-term exam that can be dropped). Students may have a more positive attitude toward the course, leading to further pursuit of the subject and more positive student course evaluations. Fewer students are likely to ask for a make-up exam, leading to fewer disputes between faculty and student over acceptable excuses for missing an exam. ${ }^{2}$ While our data set does not allow us to evaluate these benefits, we are able to identify factors affecting students' decisions regarding completion of an optional final exam.

\footnotetext{
${ }^{1}$ There are other options available to faculty such as scheduling an optional replacement test, usually the last week of class, which can be used to replace the lowest score for the semester or an oral exam as a substitute. In addition, some instructors allow students to choose their grading structure from a list of alternatives where one of these alternatives is dropping an exam. See Davis (1993) and McKechie (1999) for discussions of these and other approaches.

${ }^{2}$ Davis (1993)
} 
Further, we are able to infer whether students systematically underperform on in-term exams. A grade-dropping policy may encourage strategic behavior in some students. Some may under prepare for or even miss an exam when they know that a poor score can be dropped. Others may put forth more effort to ensure that they reach their desired course grade without having to take all the exams (dropping the final exam, for example). We explain in the next section how strategic behavior can be inferred from students' performance on the exams, without the need for a control group.

How students react to the explicit and implicit choices available to them as a result of a policy of dropping the lowest exam score is an interesting and important question. Understanding these choices can lead to better grading policies and improved learning. In general, policies that allow students multiple chances to show their competence will increase student learning, and will encourage students to continue working toward an attainable goal (Chickering and Gamson, 1991; Biehler and Snowman, 1982; Deci and Ryan, 1987; Pintrich and Schunk, 1996; Davis, 1993; Johnson, 1996). A grade-dropping policy is one way to allow multiple chances (Nelson, 1996).

Few studies of the finance or economics classrooms have examined grade-dropping policies. Sewell (2004) examines four sections of Introductory Microeconomics over one semester. Two sections (133 students) were allowed to drop their lowest score while two (130) were not. ${ }^{3}$ She finds that students who were allowed to drop their lowest test score fared worse on the comprehensive final. While the difference was statistically significant, it was small in magnitude (about 4 points on a 100 point scale). She also found that very few students in either group missed an exam (7 out of 130 in the no drop sections; 11/133 in the grade drop sections). Sewell also investigated the effect of under preparation for an exam and found "no evidence that a significantly low grade, relative to the student's other grades, is anything more than a random effect" (p. 30). Finally, students' risk attitude as measured by a five-question survey did not appear to play a significant role in students' decisions to miss exams or prepare adequately.

MacDermott (2009) looks at the impact of dropping the lowest exam on final course grade using six semesters of data (180 students) from Intermediate Macroeconomics. While the policy does not seem to affect students' grades, it does appear to alter their behavior. A substantial portion of the class, when given the option, chose to skip the last exam. ${ }^{4}$ Of the 134 students in the grade drop sections, 56 missed the last exam and an additional 23 missed a prior exam. Almost half of all students who sat for the last exam improved their grade as a result. $^{5}$

We refer the reader to Sewell (2004) for a summary of the related literature (on grading policies generally), including additional pros and cons of grade-dropping policies. Our study adds to the empirical research in several ways. First, we show how evidence of strategic behavior can be inferred by comparing actual to expected scores. We also analyze how prior exam performance affects the likelihood a student will take an optional final exam.

Our analysis is of five semesters of a large-enrollment Principles of Finance course in which two in-term exams (the first at the mid-way point, the second during the last week of classes) and a comprehensive final (one week after the second exam) were given. In all, the decisions of 1,945 students are examined. Among our findings: There is some evidence of strategic behavior by a small number of students, but the vast majority of students appear to put forth at least as much effort under a grade-dropping policy as they otherwise would. We also find that the likelihood that a student will complete the final exam is negatively associated with both the student's grade going into the final exam and the points needed for improvement of the student's course grade, but that it is positively associated with the difference between scores on the in-term exams. Lastly, we find that about half of students who take the final raised their course letter grade as a result, and, consequently, the course grade distribution shifts up slightly.

\footnotetext{
${ }^{3}$ As the author acknowledges, by assigning entire classes to one group or the other, the experiment is not randomized. For instance, athletes and student workers may have more rigid schedules and end up in a morning class.

${ }^{4}$ The last exam was not a comprehensive final, simply a fourth exam.

${ }^{5}$ We refer the reader to Sewell (2004) for a summary of the related literature (on grading policies generally), including additional pros and cons of grade dropping policies.
} 
The analysis and findings in this paper will be of interest to faculty contemplating a grade-dropping policy and to faculty and administrators interested in the effects of a grade-dropping policy on grade distribution and student behavior. The next section provides a framework for considering the effects of a grade-dropping policy. The section that follows describes the course and data used in the empirical work. Results and concluding comments are then presented.

\section{ACTUAL AND EXPECTED SCORES UNDER A GRADE-DROPPING POLICY}

A grading policy that drops the lowest score from a set of exams which includes a comprehensive final exam has an implicit weighting of course topics that is important to consider when evaluating its effects on students' choices about studying for exams and completing an optional final. To illustrate, we begin with the assertion that when faculty create an exam they necessarily, due to time and space limitations, chose a subset of questions from all of those available. For example, the faculty may select 30 questions to place on an exam (the sample) from a pool of 60 potential questions (the population). The 30 questions chosen for the exam presumably reflect a fair sample from the 60 possible and students' performance on the exam presumably will be an accurate reflection of their true understanding at that time. ${ }^{6}$ That is, if students would correctly answer $90 \%$ of the questions in the population then one would expect that they would correctly answer $90 \%$ of the questions in the sample chosen for the exam. It follows that any sample of questions from the same population will produce the same expected percentage correct, although, of course, there will be natural variation in the actual percentage from sample to sample.

Now consider a course in which two in-term exams (the $1^{\text {st }}$ given at the mid-point, the $2^{\text {nd }}$ at the end of the semester) and a comprehensive final (during finals week) are provided, with the lowest grade dropped and the two remaining scores weighted equally when calculating students' exam average. In this system, since the final is comprehensive, with half of the final exam questions covering topics from the first half of the course (call the expected percentage of correct answers to these questions $\mathrm{E}_{1}$ ) and half of the questions covering topics from the from the second half of the course $\left(\mathrm{E}_{2}\right)$, the expected final exam score will reflect the weighted performance on these two sets of questions: $\mathrm{E}_{3}=0.5 \mathrm{E}_{1}+0.5 \mathrm{E}_{2}$.

$\mathrm{E}_{1}$ also represents the expected score (percentage correct) on exam 1 and $\mathrm{E}_{2}$ represents the expected score on exam 2, since, as argued above, any sample of questions from the $1^{\text {st }}$ half of the course is expected to produce $\mathrm{E}_{1}$ and any sample of questions from the $2^{\text {nd }}$ half of the course is expected to produce $E_{2}$. Consequently, one would expect the grade on such a final exam to be between the grades on exam 1 and exam $2 .^{7}$ For example, if a student scores $70\left(=\mathrm{E}_{1}\right)$ on the first exam and $90\left(=\mathrm{E}_{2}\right)$ on the second exam, then the grade on the final should be $80 .{ }^{8}$ Examination of data for the course being studied indicates that this is a reasonable expectation (supporting details are presented later). Consequently, the score on the final exam is expected to replace a prior low score, raising the student's exam average.

We can also conclude that the only reasons for a student not to take the final are because (a) the opportunity cost of studying for it are too high, (b) the student is satisfied with their grade before the final, or (c) there is no expected improvement on the final (e.g. $E_{1}=80$ and $E_{2}=80$ or if they have already earned an A). This observation is based on the fact that the expected grade on the final $\left(\mathrm{E}_{3}\right)$ is between $\mathrm{E}_{1}$ and $\mathrm{E}_{2}$ (thereby leading to a lower prior score being replaced).

\footnotetext{
${ }^{6}$ If the questions on the exam do not fairly reflect the population of questions (are over-weighted toward a particular subset) then the exam score may not accurately reflect students' knowledge (of the population of questions). We know this happens, of course. One may attribute it to sampling error. Such sampling error may lead students to take the final, in an effort to replace an unduly low score.

${ }^{7}$ Consider the scenario in which the same questions on each of the in-term exams appear on the final exam. One would reasonably expect that, on average, a student will correctly answer the same percentage of those questions both times they are asked. An important exception would be the case in which the student studied (prepared) more for the final exam and so increased his score. If the same questions are not asked on both exams, but a similar sample is chosen, then the same result should apply. The ability to answer $70 \%$ on the first subset of questions will be replicated when an equivalent subset of questions is asked.

${ }^{8}$ If a student's knowledge is not constant over time (e.g., when a student forgets what s/he had learned or when a student learns the material too late for the first exam) then the third exam score will not be an average of the first two.
} 
In summary, if the lowest of the three exam scores is dropped and the remaining two scores are weighted equally then the implicit weighting of topics in the exam average will be either:

$$
\begin{aligned}
& \text { Exam average }=0.5 \mathrm{E}_{1}+0.5 \mathrm{E}_{2} \text { if } \mathrm{E}_{3} \text { is dropped (or not taken); or } \\
& \text { Exam average }=0.5 \mathrm{E}_{1}+0.5 \mathrm{E}_{3} \text { if } \mathrm{E}_{2} \text { is dropped (lowest) }{ }^{9} .
\end{aligned}
$$

Of course, equation 2 can be thought of as:

$$
\begin{aligned}
\text { Exam average }= & 0.5 \mathrm{E}_{1}+0.5 \mathrm{E}_{3}, \\
& =0.5 \mathrm{E}_{1}+0.5\left(0.5 \mathrm{E}_{1}+0.5 \mathrm{E}_{2}\right), \\
& =0.75 \mathrm{E}_{1}+0.25 \mathrm{E}_{2} .
\end{aligned}
$$

Equation 5 simply states that the exam average is based on $75 \%$ of the students' knowledge of exam 1 topics and $25 \%$ of exam 2 topics. So dropping a grade under this scenario has an implicit weighting that favors a student's strength. ${ }^{10}$

Notably, by dropping the lowest grade, students who do not take the final exam or who do poorly on it (equation 1) receive a grade that weights their knowledge of the course topics differently than students whose score replaces one of the prior two exams (equation 5). Doing "poorly" on the final means that $E_{3}$ is $\leq \min \left(E_{1}, E_{2}\right)$. That is, the lowest score on $\left(\mathrm{E}_{1}, \mathrm{E}_{2}\right)$ is not replaced.

Finally, note that if the lowest score were not dropped and all three exams were weighted equally, then

$$
\begin{aligned}
\text { Exam average } & =0.33 \mathrm{E}_{1}+0.33 \mathrm{E}_{2}+0.33 \mathrm{E}_{3} \\
& =0.33 \mathrm{E}_{1}+0.33 \mathrm{E}_{2}+0.33\left(\mathrm{E}_{1}+\mathrm{E}_{2}\right) \\
& =0.5 \mathrm{E}_{1}+0.5 \mathrm{E}_{2} .
\end{aligned}
$$

That is, the exam average is an equally weighted reflection of the student's knowledge of topics from both halves of the course. Equation 8 is the same as when there is no final exam (equation 1). Thus, in the end, the value of dropping an exam is potentially quite large (the weight of the lowest score is 0.25 versus 0.5 , equation 5 vs. equation $8)$.

\section{IMPACT ON STUDENT BEHAVIOR}

\section{Strategic Behavior}

The observation that the expected score on the final exam will be an average of the first two exam scores, assuming those scores reflect the student's best effort, allows us to infer strategic behavior by comparing actual scores to the expected. Missing or not fully studying for one exam is not as costly under a policy that drops the lowest grade. Some students may perform poorly on exam 1 or 2 knowing that they can drop that poor score with a good performance on the third exam. In this case, $E_{3}$ is expected to be well above their average score on exams 1 and 2. On the other hand, a grade-dropping policy may spur some students to perform their best on the first two exams. Conversations between one of the authors and many students indicate that many student's desire to do well enough on the first two exams that they won't have to take the third exam. Thus, the effect on students' behavior is not clear.

\footnotetext{
${ }^{9}$ Similarly, Exam average $=0.5 \mathrm{E}_{2}+0.5 \mathrm{E}_{3}$ if $\mathrm{E}_{1}$ is dropped (lowest).

${ }^{10} \mathrm{~A}$ policy of counting either the two in-terms (50\%-50\%) or the final exam (100\%) will remove this bias.
} 
A deviation of the actual score from the expected score can be the result of random effects or strategic behavior. With sufficiently large number of students, the individual random effects will cancel out and the resulting distribution of actual scores minus expected scores should show most students clustered around the expected score. Systematic (class-level) deviations from expected scores on exam 3 indicate that students consistently over- or underperformed on at least one of the first two exams. That is, actual scores on exam 3 that greatly differ from expected scores are a sign of altered student behavior that can be attributed to the grade-dropping policy.

Our approach to measuring strategic behavior (and the factors influencing the decision to take the final exam) differs from other studies in that other studies rely on control groups while ours relies on a comparison of actual versus expected scores for each student. With the control group method, significant differences between the exam average of the control group and the exam average of the experimental group would be inferred as evidence of strategic behavior. Our approach without a control group also allows us to infer strategic behavior. In a control group, students would have to take all three exams seriously, as no score would be dropped - thus setting the baseline against which to compare. In our study, students must take at least two of the three exams seriously. Those who do not submit exam 3 must have taken exams 1 and 2 seriously (at least to their satisfaction). For students who do submit exam 3, we can infer strategic behavior by comparing their actual and expected scores - at least two of the three exams must have been taken seriously.

We presents evidence later that shows that a small number of students appear to engage in such strategic behavior, but for the most part students perform as expected on the final exam, showing no signs of strategic behavior. A large fraction of students do, however, perform well-enough on exams 1 and 2 that they elect to skip the final (dropping that score).

\section{Factors Influencing the Decision to Take the Final}

Our analysis also examines the decision to take the final by determining the student's course grade going into the final exam, which is their course grade if they choose not to take the final (or, if their grade on the final is the one that is dropped). This allows us to calculate the percentage of students in each grade category who decide to complete the final exam, providing information about how dropping the lowest score affects the probability of a student taking the final. We employ a Probit model to measure the marginal effects of average score on the first two exams and the spread between exam 1 and 2 scores on the likelihood that a student will complete a final exam.

To mirror the decision that students made regarding whether or not to take the final exam, we calculated the student's course grade based on information available at the time students had to decide whether to take the final (all scores except the final were known). We then compared that grade to the one necessary for the student to increase their course grade one "step" (for example, from B to B+ or from B+ to A-). The difference between "current" and "potential" course grade is our "potential improvement." Of course, some students could expect to increase their grade by more than one step, for example, those who did particularly poor on one of the first two exams, but one step was the greatest reasonable improvement within reach for most students. ${ }^{11}$

When students who already have two exam grades consider whether to attempt a final exam when the lowest of the 3 exams is dropped, they consider the probability of replacing the lowest exam score with the score on the final exam and the effect of this replacement on their course grade. In particular, we will assume that they consider the score necessary to increase their current course letter grade by one "step." This necessary improvement in score on the final exam over their lowest grade on the first two exams is

$I=Z-\left(E_{1}+E_{2}\right)$,

where I represents the improvement (points) necessary on the final above the student's prior lowest grade $\left(\mathrm{I}=\mathrm{E}_{3}-\right.$ $\left.\min \left(E_{1}, E_{2}\right)\right) ; Z$ is the total points necessary to reach the next cut-off (e.g., an average of $86.5 \rightarrow Z=173$ points for a

\footnotetext{
${ }^{11}$ A two-step increase is more likely if a poor score on exam 1 or 2 does not reflect the student's true ability. This might be the case if the student did not study properly or for an appropriate amount of time; or if the student needed more time to "digest" the material.
} 
$\mathbf{B}+$ ); and $\mathrm{E}_{1}$ and $\mathrm{E}_{2}$ represent the scores on the first two exams (and the expected percentage of correct answers to questions on the final that are on the same topics). For example, a student with an 80 on the first exam and a 90 on the second (a "B" average), could replace the 80 and get a "B+" for the course if the student earns an 83 (given a minimum average of 86.5 necessary for a $\mathbf{B}+$ ).

If quizzes (or other outcomes) are required for the course grade, as they were for four of the five semesters in the study, then equation 9 becomes

$I=(Z-2 Q) / w-\left(E_{1}+E_{2}\right)$,

where $\mathrm{Q}$ represents the points from the quizzes (etc.) such that if quizzes are $10 \%$ of the final grade then $\max (\mathrm{Q})=$ 10 , and $\mathrm{w}$ is the weight given to the exam average (e.g., 0.9 for $90 \%$ ).

Since scores on all coursework except the final exam are known before students decide whether to complete the final exam, students base their decision on I from equation 10. Thus, we use this value for our analysis below. Among the empirical questions we address is whether a higher value for I means that a student is less likely to take the final. We might also expect that the higher the average on the first two exams the lower the likelihood that the student will take the final - as improvement on an already good score is progressively more difficult.

Additionally, we will examine whether the difference between scores on exams 1 and 2 influences the likelihood that a student will take the final. This is based on the observation that the final exam consists of material equally weighted from the two halves of the course. So if a student scored 90 and 80 on the first two exams and those grades are reflective of their true abilities then the student should expect to get an 85 on the final, an improvement of 5 points over the lowest exam score. A greater spread in the scores on the first two exams leads to a greater expected improvement on the final over the lowest grade. ${ }^{12}$

It may have been interesting to incorporate a variety of related variables into the analysis, similar to those utilized in Sewell (2004) and MacDermott (2009). However, this study was conducted retrospectively, before a particular research question was in mind. As a result, it is not possible to collect information on student risk attitudes, demographic characteristics, or academic data.

\section{Satisficing}

Because the expected outcome on the final exam is a grade higher than the prior lowest score, as shown in equation 5, if the student chooses not to take the final they are giving up an expected improvement in their course grade. ${ }^{13}$ This improvement should come with a modicum of additional effort. In the course being examined, one half of $E_{3}$ is based on $E_{2}$, which was just completed, and the other half on $E_{1}$ from seven weeks prior. The earlier material should be easily recalled, unless we assume that knowledge has a very short half-life - i.e. what was learned in the beginning of the course was forgotten by the end of the course and thus had to be relearned (and not simply refreshed).

A student's decision not to take the final may reflect that the student has a high opportunity cost of studying for the final or the student is satisfied with the grade they have (having no need for improvement). Each of these could be described as a form of "satisficing". According to Herbert Simon (1957), to "satisfice" means to decide that something (a choice) is "good enough" - satisfactory - while not necessarily optimal. The term has been applied in economics to consumer searches, profit maximization, and financial decision making. In the case of grades, students may evaluate a certain course grade as sufficient for their goals, even though it is not maximal (in the sense that they

\footnotetext{
12 If one or both scores on the first two exams is/are not reflective of the student's true ability then the student has greater (true ability above actual score) or less (true ability below actual score) incentive to take the final.

${ }^{13}$ It is presumed that optimizing students seek to maximize their expected course grade. It is altogether reasonable to believe students may have some other focus such as overall GPA or even utility. While interesting, the absence of related data such as concurrent course load and grade point average make this line of investigation impossible.
} 
could achieve a higher grade if they wanted). ${ }^{14}$

\section{DATA}

Data for this study come from five semesters of a large section Principles of Finance course taught by one of the authors at a medium-sized public research university in the northeastern U.S. from Fall 2003 to Fall 2005. Each semester, 350 to 400 students were enrolled in the only two sections of the course offered, 1,945 students in all for the period of the study. All the sections studied were taught by the same instructor and used the same syllabus, text, topics, and teaching methods. Based on a survey done during one of the semesters, we know that students were almost entirely upperclassmen (99\%) and either business majors (49\%) or minors (48\%). More than half (56\%) were male and more than half $(58 \%)$ had a cumulative GPA above $3.00 .{ }^{15}$

Each semester, three exams, including two in-terms and a comprehensive final, were administered, with an equal weighting of the highest two scores constituting the student's exam average. All exams were multiple choice, with each in-term containing between 30 and 40 questions and the final containing 50 to 60 questions. The in-terms each covered half the course content. The first exam was administered at the mid-point of the semester, the second during the last week of classes. The final was an equal mix of questions based on topics from the two halves and was administered during final exams week, within about one week of the second exam. Course letter grades with plus and minus modifiers were assigned based on numerical grades ranging from 0 to 100 . For all semesters the final numerical course grade was rounded to the nearest integer before a letter grade was determined. The minimum rounded score necessary for each letter grade was A:93, A-:90, B+:87, B:83, B-:80, C+:77, C:73, C-:70, D+:67, D:60. D- was not given. These cut-offs were known to students when they decided whether to take the final exam.

\section{RESULTS}

\section{Strategic Behavior}

Table 1 presents summary statistics of students who took the third (final) exam. The students are grouped according to their performance relative to their expected score. The evidence of strategic behavior is clear for some students but not apparent for most. Two thirds of students scored within 10 percentage points of their expected score and the mean difference between actual and expected is less than one point. Thus, the bulk of students appeared to put forth consistent effort on all three exams. Only $13.9 \%$ of students scored 10 or more points above their expected score (indicating that they seriously underperformed on a prior exam). In addition, one-third of all students did well enough on the first two exams that they did not even take the final. Thus, more than $80 \%$ of all students show no sign of strategic behavior that represents under provision of effort.

The fat tails are indicators of students who may have engaged in strategic behavior: $3.1 \%$ of students scored more than 20 points above their expected score and $3.7 \%$ scored more than 20 points below their expected score. But this is a quite small portion of students. Of students who scored more than 20 points above their expected score, 81 percent had missed a prior exam (40 students out of 1945). Most of the strategic behavior in this group consisted of missing an exam entirely, making up the missed score later.

\footnotetext{
${ }^{14}$ We recognize that colleges may differ in their grading policies in a way that will influence students' choices in this regard. At the university where the grades being studied were produced, if a student repeats a course (takes the same course more than once) then the all course grades are averaged. So students always have reason to maximize their grade. However, we know that at some schools if a student earns an F and repeats the course (earning a higher grade) the F is not calculated in the student's GPA. However, if they earned a D initially and repeated the course, both the D and the higher grade are included. Thus, at the university being studied, but not necessarily elsewhere, a student with an F going into the final has every reason to take the final. Furthermore, at some colleges, but not the one being studied here, if a student needs at least a $\mathrm{C}$ for the course to count toward their major and they currently have an F, they might not take the final, even if a D is possible, if it does them no good in the long run. At the university being studied, students need to maintain a B-average in all Business School courses (of which the course being studied is one). Thus, again, these students have every incentive to take the final exam.

${ }^{15}$ We do not have demographic information for each semester. As a result, we cannot determine the effects of major, GPA, or course load on students' choices.
} 
Table 1 - Performance of students who took the final exam (exam 3)

\begin{tabular}{|c|c|c|c|c|c|c|c|}
\hline Group & $\mathrm{N}$ & $\begin{array}{r}\text { Pct of } \\
\text { students }\end{array}$ & $\begin{array}{r}\text { Average } \\
\text { Actual } \\
\text { minus } \\
\text { expected on } \\
\text { exam } 3 *\end{array}$ & $\begin{array}{l}\text { Exam 1 } \\
\text { Average }\end{array}$ & $\begin{array}{l}\text { Exam } 2 \\
\text { average }\end{array}$ & $\begin{array}{l}\text { Exam } 3 \\
\text { average }\end{array}$ & $\begin{array}{l}\text { Pct with } \\
\text { prior zero }\end{array}$ \\
\hline More than 20 points below expect $\epsilon$ & 41 & $3.1 \%$ & -28.7 & 82.2 & 77.9 & 51.4 & $0.0 \%$ (0 students) \\
\hline 10 to 20 points below expected & 209 & $15.8 \%$ & -13.6 & 79.8 & 76.4 & 64.5 & $0.0 \%$ (0 students) \\
\hline 10 below to 10 above expected & 892 & $67.3 \%$ & -0.1 & 77.9 & 74.5 & 76.1 & $0.3 \%$ (3 students) \\
\hline 10 to 20 points above expected & 135 & $10.2 \%$ & 13.3 & 71.2 & 67.3 & 82.6 & $3.7 \%$ (5 students) \\
\hline More than 20 points above expecte & 49 & $3.7 \%$ & 34 & 62.3 & 21.5 & 75.9 & $81.6 \%$ (40 students) \\
\hline Grand Average & \multicolumn{2}{|c|}{$\begin{array}{r}1326(68 \% \text { of all } \\
\text { students })\end{array}$} & -0.5 & 77.1 & 72.2 & 74.2 & $3.6 \%$ \\
\hline
\end{tabular}

*Note: (Exam 3 score minus average on exams 1 and 2)

The students who scored more than 20 points below their expected score by and large simply took the final exam lightly. Students in this group generally had very good scores on the first two exams but scored very poorly on the final. Their strategic approach appears to have been to take the final exam without much studying since the score on the exam could always be dropped. ${ }^{16}$

Of the 344 students who scored 10 to 20 points above or below their expected score (209 and 105 , respectively), only 5 (1.5 percent) missed a prior exam. For the rest, the improvement/decline can be attributed to either improved/poorer studying or better/worse luck than they had on a prior exam (i.e., being asked the subset of questions to which they knew/did not know the answer).

Thus, the type of strategic behavior that could negatively affect student learning (e.g., reduced studying for the first two exams) appears to be practiced by only a small subset of students. ${ }^{17}$ The bulk of students show signs of either increased effort on the first two exams (so as to avoid an additional exam, which could be considered a form of strategic behavior) or no change in effort.

Another way to show the distribution of scores in Table 1 is by comparing the distribution of scores to the normal distribution, as in Figure 1 . Normality of actual scores is clearly rejected, using the standard criteria ${ }^{18}$, because of the high frequency of scores around the expected score and the larger than 'normal' (although still relatively small) share of scores above expected. Thus, some strategic behavior is occurring - as evidenced by the fat tails - even though it appears that most students fall near the expected value (are not engaging in strategic behavior).

\section{The Decision to Take the Final}

Table 2 shows, by semester the count of students by grade entering the final. Table 3 shows the percentage of each group that completed the final exam. Overall, $68 \%$ of students submitted a final exam. Of the 193 students who had an A-going into the final, just over half, $52 \%$, decided to take the final exam. This percentage increased as the grade going into the final decreased: $70 \%$ of those with a $\mathbf{B}+$ completed a final exam, $75 \%$ of those with a $\mathrm{B}$, and

\footnotetext{
${ }^{16}$ One student scored as low as $3.33 \%$. This student had scores of 75 and 80 on the first two exams and likely concluded shortly after arriving for the exam, that they were unprepared and unlikely to improve their score.

${ }^{17}$ Of course, students who reduce their study effort for one of the first two exams have to make up for it by studying for a comprehensive final.

${ }^{18}$ The Cramer-von Mises statistic is $1.35(\mathrm{p}=0.0000)$; Watson $=1.28(\mathrm{p}=0.0000)$; and Anderson-Darling $=10.42(\mathrm{p}=0.0000)$, as calculated in EViews 6.
} 
so on, until it declines slightly for those with a $\mathrm{D}$, and more dramatically for those failing the course going into the final. ${ }^{19}$

Figure 1

\section{Distribution of actual score on exam 3 minus expected score} compared to the normal distribution.

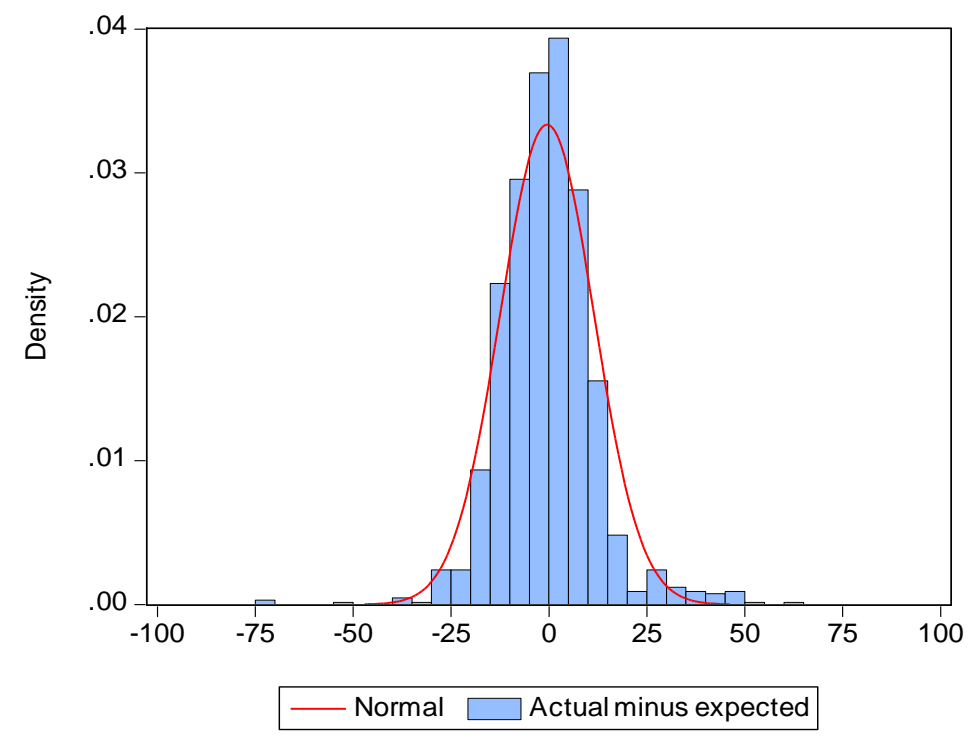

Table 2: Number of Students

\begin{tabular}{|c|c|c|c|c|c|c|}
\hline Grade going in & F-03 & S-04 & F-04 & S-05 & F-05 & Total \\
\hline $\mathrm{A}$ & 85 & 53 & 63 & 20 & 24 & 245 \\
\hline A- & 64 & 39 & 35 & 22 & 33 & 193 \\
\hline $\mathrm{B}+$ & 46 & 44 & 57 & 29 & 68 & 244 \\
\hline $\mathrm{B}$ & 67 & 41 & 65 & 37 & 47 & 257 \\
\hline B- & 26 & 40 & 53 & 26 & 49 & 194 \\
\hline $\mathrm{C}+$ & 30 & 30 & 35 & 36 & 48 & 179 \\
\hline $\mathrm{C}$ & 35 & 32 & 38 & 53 & 26 & 184 \\
\hline $\mathrm{C}-$ & 13 & 14 & 17 & 30 & 37 & 111 \\
\hline $\mathrm{D}+$ & 10 & 13 & 7 & 30 & 18 & 78 \\
\hline $\mathrm{D}$ & 15 & 13 & 13 & 44 & 25 & 110 \\
\hline $\mathrm{E}$ & 16 & 29 & 25 & 51 & 29 & 150 \\
\hline Total & 407 & 348 & 408 & 378 & 404 & 1945 \\
\hline
\end{tabular}

The less than $100 \%$ rate may be evidence of "satisficing." It appears in our study that a great many students are happy to have a certain grade less than the maximum attainable (whatever that may be for the particular student), as they forego the opportunity to improve their course letter grade. Almost 50 percent of students with an A- forego the opportunity to earn an $\mathbf{A}$, which for some meant scoring less than two points higher on $\mathrm{E}_{3}$ than their prior lowest score -- which was mathematically likely, as we discussed earlier. This is true for all other grade categories, as well.

\footnotetext{
${ }^{19}$ The improvement necessary to raise one's grade one "step" (I from equation 10) rises for D \& F because the course did not use a "-." modifier for the D letter grade and modifiers are eliminated on the F. This might explain the drop off in the percentage of students who take the final.
} 
Table 3: Percentage of Students Who Completed A Final Exam, by Course Grade before Final

\begin{tabular}{ccccccc}
\hline $\begin{array}{c}\text { Grade } \\
\text { going in }\end{array}$ & $\mathbf{F - 0 3}$ & $\mathbf{S - 0 4}$ & $\mathbf{F - 0 4}$ & $\mathbf{S - 0 5}$ & \multicolumn{2}{c}{$\begin{array}{c}\text { Weighted } \\
\text { average }\end{array}$} \\
\hline A & $0 \%$ & $0 \%$ & $0 \%$ & $0 \%$ & $0 \%$ & $0 \%$ \\
A- & $61 \%$ & $51 \%$ & $43 \%$ & $45 \%$ & $48 \%$ & $52 \%$ \\
B+ & $78 \%$ & $66 \%$ & $79 \%$ & $45 \%$ & $71 \%$ & $70 \%$ \\
B & $70 \%$ & $71 \%$ & $85 \%$ & $62 \%$ & $83 \%$ & $75 \%$ \\
B- & $88 \%$ & $78 \%$ & $96 \%$ & $65 \%$ & $76 \%$ & $82 \%$ \\
C+ & $90 \%$ & $93 \%$ & $94 \%$ & $64 \%$ & $88 \%$ & $86 \%$ \\
C & $94 \%$ & $88 \%$ & $87 \%$ & $81 \%$ & $81 \%$ & $86 \%$ \\
C- & $85 \%$ & $100 \%$ & $82 \%$ & $80 \%$ & $86 \%$ & $85 \%$ \\
D+ & $100 \%$ & $100 \%$ & $100 \%$ & $90 \%$ & $94 \%$ & $95 \%$ \\
D & $80 \%$ & $92 \%$ & $100 \%$ & $91 \%$ & $92 \%$ & $91 \%$ \\
E & $63 \%$ & $79 \%$ & $76 \%$ & $84 \%$ & $86 \%$ & $80 \%$ \\
\hline Overall & $61 \%$ & $65 \%$ & $70 \%$ & $70 \%$ & $74 \%$ & $68 \%$
\end{tabular}

Students may be evaluating the cost of attaining the higher grade, measured mostly by study time, against the benefits. If higher performance on exams requires an increasingly higher study time, i.e., increasing marginal cost of studying $\left(\right.$ Grade $=f\left(\right.$ Studytime $\left.\left.^{b}\right), b<1\right)$, then raising one's score from 90 to 95 requires more study time than raising one's score 5 points from 85 to 90 . Given that the student may have exams in other courses, the additional time studying could be spent elsewhere and so has real cost.

Students were more likely to take the final the greater the difference between exam one and exam two scores. We see this in Figure 2, which shows the percentage of students who took the final exam for each level of difference between exam 1 and exam 2 scores. A large spread might be the result of a "bad exam day" or poor preparation for one of the exams, leading students to think they can improve upon that poor score (with better luck or more effort, as the case may be). The likelihood that a student will complete the final exam is strongly related to the spread. Visual inspection suggests the effect is stronger if the first exam score is higher than the second (the negative range in the diagram).

Figure 2

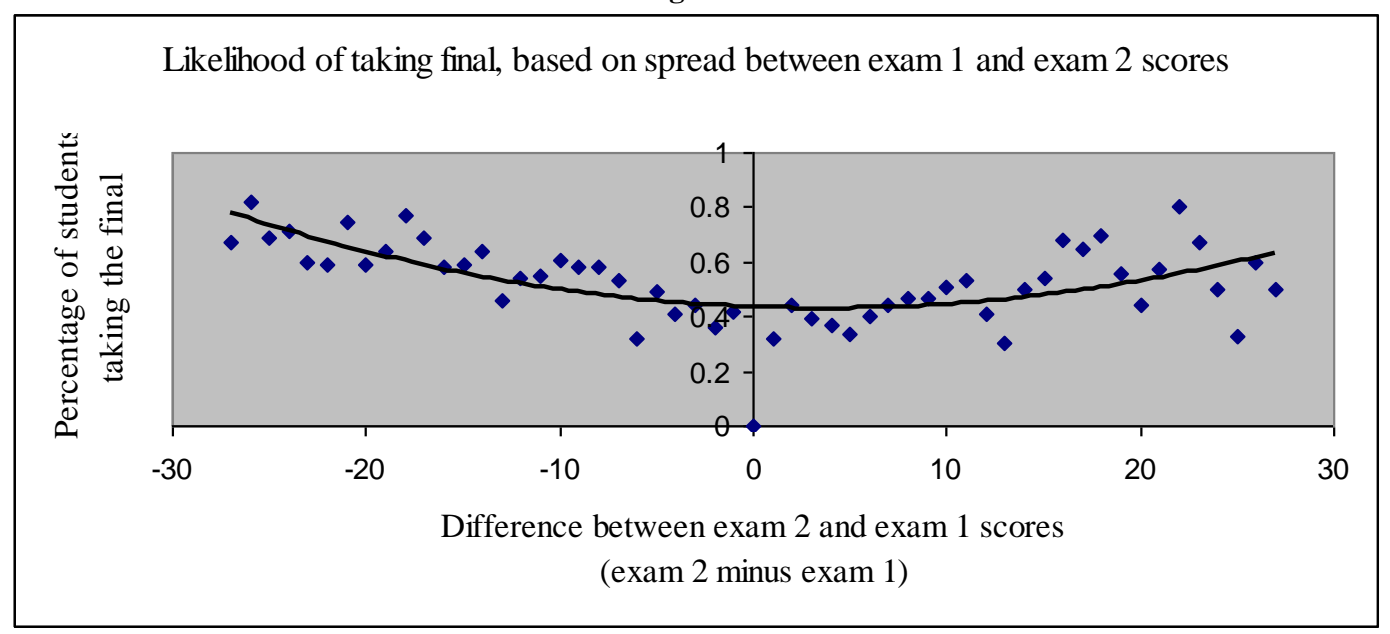

Note: Students were grouped by difference between exam 1 and 2 scores. Thus, each observation plotted represents an average of many students.

To examine these possibilities more closely we use a probit model to measure the factors that influence a student's decision to take the final exam. The following probit equation is tested: 
$\operatorname{Prob}($ take final $=1)=f\left(\mathrm{I}\right.$, average $\left.\left(\mathrm{E}_{1}, \mathrm{E}_{2}\right),\left(\mathrm{E}_{1}-\mathrm{E}_{2}\right)\right)$

where $I$ is the number of points needed on the final exam to improve the final grade in the class, average $\left(\mathrm{E}_{1}, \mathrm{E}_{2}\right)$ is the average of the in-term exams, and $\left(\mathrm{E}_{1}-\mathrm{E}_{2}\right)$ is the difference in the scores on the two in-term exams. ${ }^{20} \mathrm{We}$ perform this analysis on the full sample using the absolute value of the difference in the exam scores $\left(\left|E_{1}-E_{2}\right|\right)$.

The results, found in Table 4, show each of these factors significantly contributed to the student's decision. The greatest effect was from the number of points needed to improve their final grade in the class (value for I in equation 10). As the challenge of improving their course grade increased, students were less likely to sit for the final exam. In addition, students appear to become satisfied with their grade. As their performance on the first two exams (and, in turn, their course grade) rises they are less likely to take the final, regardless of how close or far the next grade might be. Lastly, students view the final as an opportunity to make up for a poor performance, or simply recognize the implicit expected improvement (equation 5 vs. equation 1). As the difference between the two exam scores rises, students are more likely to take the final exam.

Table 4

Probit analysis of students completing the final exam.

\begin{tabular}{|c|c|c|c|}
\hline & Full sample & $\mathrm{E}_{1}-\mathrm{E}_{2}>0$ & $\mathrm{E}_{1}-\mathrm{E}_{2}<0$ \\
\hline \multirow[t]{2}{*}{ Constant } & $4.080^{*}$ & $3.228 *$ & $5.466^{*}$ \\
\hline & $(11.418)$ & $(7.559)$ & $(7.743)$ \\
\hline \multirow[t]{2}{*}{ I } & $-0.107 *$ & $-0.104 *$ & $-0.113 *$ \\
\hline & $(-8.088)$ & $(-6.587)$ & $(-4.398)$ \\
\hline \multirow{2}{*}{ Average $\left(\mathrm{E}_{1}, \mathrm{E}_{2}\right)$} & $-0.044 *$ & $-0.034 *$ & $-0.061 *$ \\
\hline & $(-10.385)$ & $(-6.442)$ & $(-7.440)$ \\
\hline \multirow{2}{*}{$\left(\mathrm{E}_{1}-\mathrm{E}_{2}\right)$} & $0.023^{*}$ & $0.024 *$ & $0.024 *$ \\
\hline & $(5.744)$ & $(5.126)$ & $(2.618)$ \\
\hline Log Likelihood & -1113.224 & -636.631 & -438.070 \\
\hline $\mathrm{N}$ & 1,945 & 1,137 & 765 \\
\hline \multicolumn{4}{|c|}{ z-statistics are provided below in parentheses. } \\
\hline
\end{tabular}

Based upon visual inspection of Figure 2, we speculate that students were less responsive to difference in exam score when exam 2 was higher. We investigate this by breaking the data into two subsets: $E_{1}-E_{2}>0$ (Column 2 ) and $E_{1}-E_{2}<0$ (Column 3). It shows the results are virtually identical. While the difference in exam performance is an important factor when deciding to take the final exam, which exam was higher was not.

Additional analysis could have been performed if we had complete student demographic and academic data, but they were not available. While the lack of such data limits the questions we can address (e.g., do business

\footnotetext{
${ }^{20}$ The results do not change appreciably if we replace 'average of in-term exams' with 'course grade going in to the final.' These results are available on request.
} 
students behave differently than others?) the absence of variables such as course load, major, and GPA will not affect the findings significantly. Excluding variables such as course load, which are uncorrelated with the other explanatory variables, has minor effect. According to Wooldridge (2002, p. 470), while the estimates of the coefficients $(\beta)$ in a probit are inconsistent given an omitted variable, $\beta / \sigma$ is not, and "we should remember that, in nonlinear models, we usually want to estimate partial effects and not just parameters. For the purposes of obtaining the directions of the effects or the relative effects of the explanatory variables, estimating $\beta / \sigma$ is just as good as estimating $\beta$." Further, "probit of $\mathrm{y}$ on $\mathrm{x}$ consistently estimates the average partial effects, which is usually what we want." Certainly, "absolute value of the difference in exam performance" and "points needed for higher grade" (from equation 11) are not correlated with missing demographic information such as major, gender, and SAT. "Average of in-term exams" may, on the other hand, be correlated with variables such as GPA and major, with an effect that is less clear but likely is small (Cramer, 2005). The signs will be unchanged and the conclusions (based on the signs) are the same.

\section{Grade Inflation}

Lastly, we compare the distribution of course grades with and without the grade-dropping. One concern with the practice of dropping the lowest grade is the potential for grade inflation. We find that, on average, scores on the final exam are three and a half points above the lowest of the first two exam scores, as expected (ignoring students who missed one of the first two exams). As Fig 1 shows, most scores on the final exam were near the exam 1 and 2 average (the expected score). Overall, 803 students who took the final replaced a low score on one of the first two exams. This represents $60.6 \%$ of those who took the final and $41.3 \%$ of the entire class. 650 students (49\% of students who took the final and $33.4 \%$ of all students) improved their course grade as a result (details in Table 5). Those most likely to replace a low score with their final exam score were, of course, the ones who did very poorly on one of the first two exams, as shown in Figure 3. Nevertheless, excluding students who missed either exam 1 or 2 , the class GPA with the grade-dropping policy was 2.87, compared to 2.66 without dropping the lowest score (based on the average of the first two exams and no third exam). That is, the class GPA of actual course grades was 2.87, while the GPA of grades going into the final (based on just exams 1 and 2) was 2.66. Thus, overall grade inflation seems small. Further, it seems to be heavily concentrated at the lower end of the grade distribution. Only moderate gains were made by those with high grades heading in to the final while much greater strides were made by those with lower in-term grades.

Table 5

Percentage of students (who took the final exam) who raised their course grade as a result.

\begin{tabular}{lrrrrrr}
\hline Grade & & & & & & Weighted \\
going in & F-03 & S-04 & F-04 & S-05 & F-05 & average \\
\hline A & n/a & n/a & n/a & n/a & n/a & n/a \\
A- & $38 \%$ & $10 \%$ & $47 \%$ & $10 \%$ & $25 \%$ & $29 \%$ \\
B+ & $47 \%$ & $17 \%$ & $60 \%$ & $23 \%$ & $27 \%$ & $39 \%$ \\
B & $47 \%$ & $45 \%$ & $51 \%$ & $39 \%$ & $29 \%$ & $43 \%$ \\
B- & $83 \%$ & $58 \%$ & $53 \%$ & $47 \%$ & $46 \%$ & $56 \%$ \\
C+ & $63 \%$ & $50 \%$ & $76 \%$ & $48 \%$ & $56 \%$ & $59 \%$ \\
C & $42 \%$ & $39 \%$ & $61 \%$ & $42 \%$ & $45 \%$ & $46 \%$ \\
C- & $64 \%$ & $64 \%$ & $64 \%$ & $25 \%$ & $57 \%$ & $51 \%$ \\
D+ & $80 \%$ & $62 \%$ & $71 \%$ & $59 \%$ & $65 \%$ & $65 \%$ \\
D & $58 \%$ & $50 \%$ & $54 \%$ & $40 \%$ & $41 \%$ & $46 \%$ \\
E & $50 \%$ & $61 \%$ & $74 \%$ & $67 \%$ & $68 \%$ & $66 \%$ \\
\hline Overall & $52 \%$ & $44 \%$ & $59 \%$ & $44 \%$ & $45 \%$ & $49 \%$
\end{tabular}


Figure 3

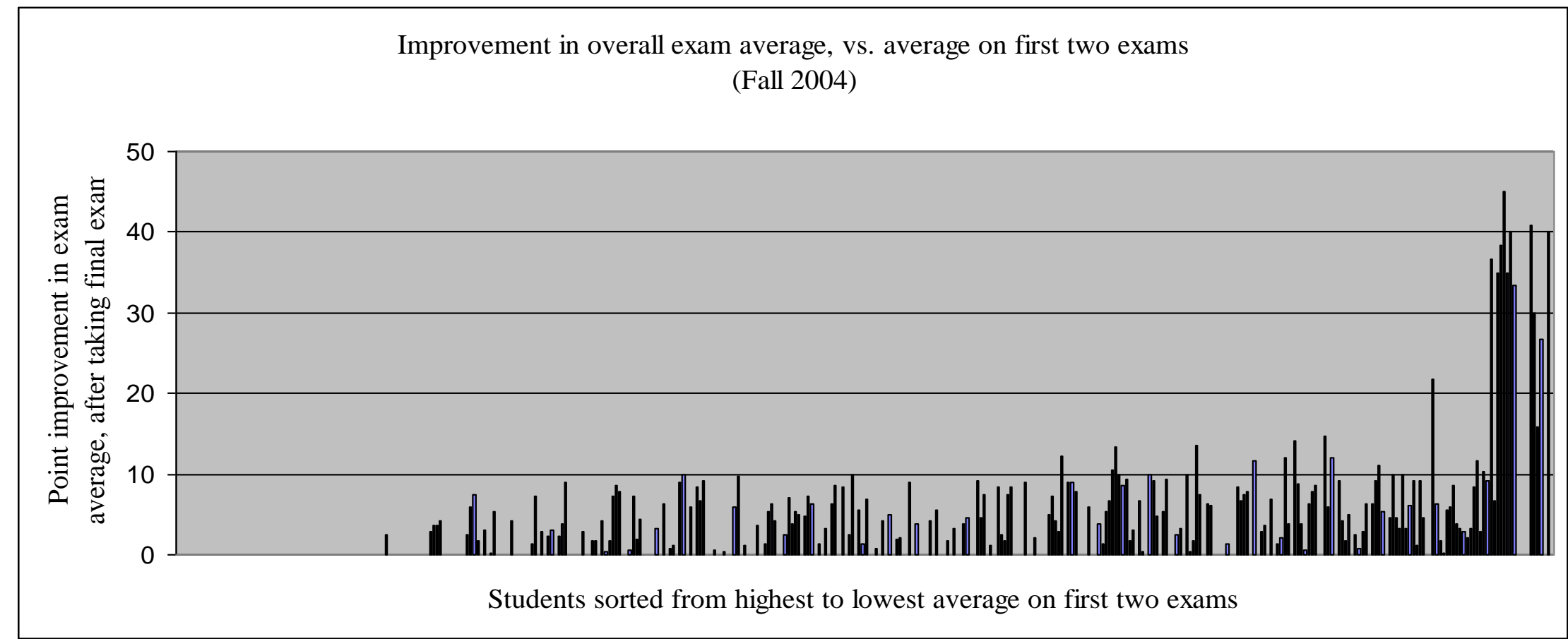




\section{CONCLUSIONS}

Our examination of the choices of 1,945 students over five semesters in a class in which the lowest exam score is dropped provides evidence that a small number of students engage in strategic behavior by under preparing for or altogether missing an exam whose score they know can be dropped. The performance of most students, though, shows no evidence of strategic behavior. We do find evidence that students satisfice - that is, achieve a level of performance that is satisfactory (or sufficient) but less than optimal.

Students were less likely to take the final exam the higher their performance on the first two exams and the greater the number of points required to achieve a higher course letter grade, while they were more likely to sit for the final exam the greater the difference between the first two exam scores.

Dropping the lowest grade leads to a modest upward shift in the grade distribution, but the bulk of the increase in grades occurs at the lower end of the distribution - the dropping policy provides students who did poorly on one of the prior exams a second chance to demonstrate their understanding of the course material.

No doubt, more research can be done on the topics of grade-dropping, student satisficing, and strategic behavior by students generally. While there is no reason to believe that findings in this paper are not generalizable, future research might broaden the analysis to other universities and courses. Future research could also measure some of the other benefits that may be associated with a grade-dropping policy that we were unable to with our data set. ${ }^{21}$ Of particular interest is the relative importance of satisificing, opportunity cost of studying, and risk attitudes, and mis-measurement on prior exams as reasons for taking or not taking the final. Greater understanding of these and related issues will not only lead to improved grading policies, but improved instruction and greater learning.

\section{AUTHOR INFORMATION}

Raymond MacDermott (BA, Ithaca College, MA, University of Pittsburgh, PhD, Rutgers University) is an Associate Professor of Economics at the Virginia Military Institute. He has published research on the effects of regional trade agreements and environmental regulations on foreign direct investment as well as research on grading policies.

Lester Hadsell is an Assistant Professor of Economics at the State University of New York, College at Oneonta. His primary areas of research are economics education, wholesale electricity markets, and local economies. His research has appeared in journals such as Applied Economics, Energy Journal, Journal of Futures Markets, Journal of Education for Business, and Advances in Financial Education, among others. He has a Ph.D. in economics from Rensselaer Polytechnic Institute, and an M.A. and a B.A. in economics from SUNY Albany.

\section{REFERENCES}

1. Biehler, R. F. and J. Snowman. 1982. Psychology Applied to Teaching. 4th edition. Boston: Houghton Mifflin Company.

2. Chickering, A. and Z. F. Gamson. 1991. Applying the Seven Principles for Good Practice in Undergraduate Education. New Directions for Teaching and Learning. Number 47, Fall. San Francisco: Jossey-Bass Inc.

3. Cramer, J.S. (2005) "Omitted Variables and Misspecified Distrubances in the Logit Model." Tinbergen Institute Discussion Paper. Accessed December 2008 at http://www.tinbergen.nl/discussionpapers/05084.pdf.

4. $\quad$ Davis, B. 1993. Tools for Teaching. San Francisco: Jossey-Bass.

5. Deci, E. L., and R. Richard. 1987. "The Support of Autonomy and the Control of Behavior." Journal of Personality and Social Psychology 53: 1024-1037.

6. Johnson, J. 1996. "Individualization of Instruction." Faculty Focus, Fall.

\footnotetext{
${ }^{21}$ We also no longer teach the large lecture courses examined in this paper and so are unable to engage in some of the suggestions.
} 
7. MacDermott, R. 2009. "The Effects of Dropping a Grade in Intermediate Macroeconomics." New York Economic Review 40: 40-49.

8. McKeachie, W. J. 1999. Teaching Tips. Houghton Mifflin Company.

9. Nelson, C. 1996. "Student Diversity Requires Different Approaches to College Teaching, Even in Math and Science." American Behavioral Scientist 40(2): 165-176.

10. Pintrich, P. R. and D. H. Schunk. 1996. Motivation in Education: Theory, Research, and Applications. Englewood Cliffs, NJ: Prentice Hall

11. Sewell, E. 2004. "Grade Dropping: An Empirical Analysis." Journal of Economic Education 35(1): 24-34.

12. Simon, H. A. 1957. Models of Man: Social and Rational. New York: Wiley.

13. Wooldridge, Jeffery M. (2002). Econometric Analysis of Cross Section and Panel Data. Cambridge, MA. MIT Press. 
NOTES 